\title{
To study the maternal and perinatal outcome following vaginal birth after caesarean section after one previous lower segment caesarean section
}

\author{
Latika $^{1}$, Gurcharan Kaur ${ }^{2}$, Sukhbir Singh $^{3}$
}

\author{
${ }^{1}$ Department of Obstetrics \& Gynaecology, PT. B. D. S. PGIMS, Rohtak, Haryana, India \\ ${ }^{2}$ Department of Obstetrics \& Gynaecology, Kasturba Hospital, Delhi, India \\ ${ }^{3}$ Department of Hospital Administration cum Deputy Medical Superintendent, PT. B. D. S. PGIMS, Rohtak, Haryana, \\ India
}

Received: 09 March 2015

Accepted: 23 March 2015

\section{*Correspondence:}

Dr. Latika,

E-mail: latika.duhan@gmail.com

Copyright: ( $)$ the author(s), publisher and licensee Medip Academy. This is an open-access article distributed under the terms of the Creative Commons Attribution Non-Commercial License, which permits unrestricted non-commercial use, distribution, and reproduction in any medium, provided the original work is properly cited.

\begin{abstract}
Background: The pronouncement "Once a caesarean, always a caesarean" by Dr. Edward Craigen in 1916, established elective repeat caesarean section as standard of care. Over the years, there have been ample studies which have concluded relative safety of a vaginal birth in most women after a low transverse caesarean section. Hence vaginal birth after caesarean appears to be the most productive approach to lowering the caesarean rate. A prospective study was carried out to evaluate maternal and perinatal outcomes in patients undergoing VBAC with history of previous one LSCS.

Methods: The study was undertaken in the department of Obstetrics and Gynaecology at Kasturba hospital, Delhi. Total of fifty cases of previous one LSCS who were eligible for vaginal deliveries were recruited and a prospective study was performed.

Results: It was found that out of total fifty cases, 39 (78\%) patients delivered vaginally and $11(22 \%)$ patients had to be taken up for emergency LSCS for various indications. Significant association of success of VBAC was noted in patients with history of prior VBAC as compared to patients without history of prior VBAC (P value being $<0.0001)$ There was more maternal and neonatal morbidity in case of failed VBAC as compared to successful VBAC. $18.1 \%$ neonates had NICU stay in Failed VBAC cases as compared to successful VBAC $(2.56 \%)$.

Conclusions: In carefully selected patients, under proper settings, VBAC can be safely practiced, thereby bringing down the rising caesarean rates.
\end{abstract}

Keywords: Caesarean section, VBAC, Neonate

\section{INTRODUCTION}

The statement "Once a caesarean, always a caesarean" by Dr. Edward Craigen in 1916, recognized elective repeat caesarean section as standard of care. ${ }^{1}$ The high frequency of classical caesarean section, deficiencies of blood banks \& insufficient means of foetal monitoring made his proclamation an intelligent argument for that period. In the prevailing years, there were changes in the type of uterine incision in addition to various advances in technology. It permitted precise monitoring of foetus and mother, making vaginal birth after caesarean a relatively easy job for both patient as well as healthcare provider. There have been various studies which have concluded relative safety of a vaginal birth in most women after a low transverse caesarean section. ${ }^{2}$ Therefore, vaginal birth after caesarean appears to be the most useful approach for reducing the caesarean rate. Vaginal 
delivery is associated with less risks, requires less anesthesia, poses a lesser possibility for postpartum morbidity like fever, blood transfusions, postpartum infections, involves a shorter hospital stay, is more affordable, and encourages earlier and better bonding between mother and infant. There have been various studies which have reported success of VBAC as $60 \%$ $80 \%$ in women attempting vaginal birth after a previous Cesarean section. ${ }^{3}$ The main risk in post caesarean pregnancy is the danger of rupture of scar. The review of literature is full of studies which clearly show that the incidence of rupture of lower uterine segment scar in patient having a VBAC is very low, 0.3\% (Phelan et.al., 1989). ${ }^{4} 0.49 \%$ (Holland et.al., 1992). ${ }^{5}$ Also, various studies point towards the fact that there is high maternal morbidity in repeat caesarean as compared to vaginal delivery (Ritchie 1995). ${ }^{6}$ The risk of mortality into subsequent pregnancies is not immediately recognized. Thus, VBAC should be encouraged in well-equipped centers having round the clock facility of blood bank, anesthetist and availability of specialist Obstetrician.

\section{Aim and objectives}

- To study maternal and perinatal outcome following Vaginal Birth After Caesarean section (VBAC) in a previous one LSCS patient.

\section{METHODS}

\section{Sample size}

A total of fifty (50) patients of previous one LSCS were taken up for the study.

\section{Study setting}

The study was carried out in the Obstetrics \& Gynecology department, Kasturba Hospital, Delhi

\section{Inclusion criteria}

The women with previous one LSCS having single live fetus, cephalic presentation, have reached thirty eight (38) weeks of gestation, with adequate pelvis (No CPD) and only booked patients were included in the study.

\section{Exclusion criteria}

The women who had more than one caesarean birth, patients with CPD, APH, vertical/inverted T, classical incision of previous caesarean section, previous uterine surgery such as hysterotomy or previous myomectomy, cervicopexy, Manchester repair etc. or previous uterine perforation were excluded from the study.

\section{Technique}

It was a prospective study. The informed consent was taken from every participant. Proper detailed history was obtained with special emphasis on past obstetric history, history of any VBAC, indication of prior caesarean, whether elective or emergency, duration of labour and the stage at which caesarean section was carried out. In case of emergency caesarean the indication of prior caesarean, any per operative or postoperative complications encountered. Any significant past, personal or family history was also enquired. The detailed general as well as per vaginal examination was done in all cases at 38 weeks or when patient went in labour. The patients were instructed to report to the hospital immediately in case of any abdominal pain, any vaginal bleeding, abnormal foetal movements, leaking per vaginum or any fainting attacks. All patients for vaginal delivery were admitted at 40 weeks or earlier if any complications arise. After admission, routine investigations and special investigations wherever necessary were carried out, one unit blood was arranged and kept cross matched. All the patients were followed during labour. A partogram was prepared to watch for progress of labour. All patients with successful vaginal delivery were observed in the immediate puerperium for any complication. If during trial of vaginal delivery patient developed complications like scar tenderness, or signs of imminent rupture, unsatisfactory progress of labour or foetal distress, than an emergency LSCS was done. At discharge, general examination, vaginal examination and per speculum examination was done. Patients were called for follow up after 6 weeks. Regarding newborn, immediately after birth, routine nasopharyngeal suction was done in all cases. The apgar score at one minute and five minutes was calculated. Any resuscitative methods (if employed) were noted. All neonates were examined in details. All babies were followed up at six (6) weeks.

\section{Data analysis}

The data was compiled and results were critically analyzed. The statistical analysis was performed by the $\mathrm{X}^{2}$ (Chi-squire) test \& $\mathrm{Z}$ test. A $\mathrm{P}$ value of $<0.05$ was considered statistically significant.

\section{RESULTS}

\section{Final outcome of trial of $V B A C$}

Out of total fifty (50) cases, thirty nine (78\%) patients delivered vaginally and out of them thirteen patients (13) patients had history of prior VBAC. The rest eleven (22\%) patients had to be taken up for emergency LSCS (Figure 1).

\section{Success of trial of vaginal delivery in relation to past obstetrics history (VBAC group)}

In our study, there were thirteen patients (26\%) who had history of prior VBAC and majority of them had successful vaginal delivery $(92 \%)$. The remaining thirty seven $(74 \%)$ patients had no history of VBAC and most of them $(75 \%)$ had successful VBAC. Significant 
association of success of VBAC was noted in patients with history of prior VBAC as compared to patients without history of prior VBAC ( $\mathrm{P}$ value being <0.0001) (Figure 2).

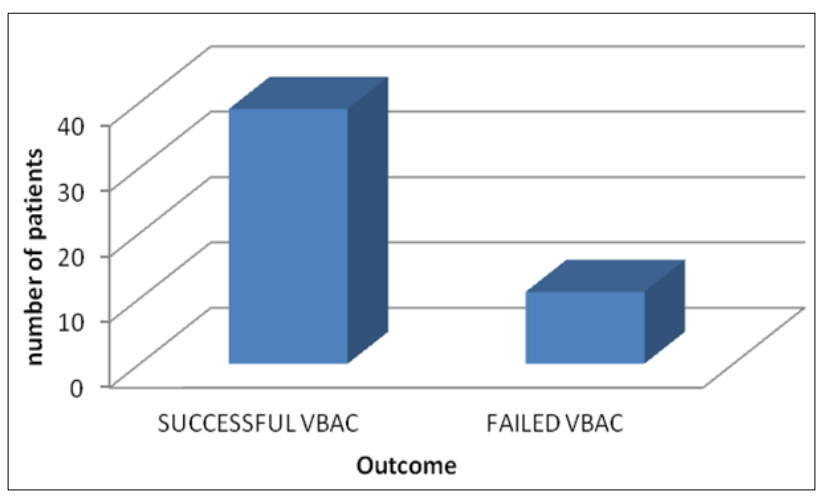

Figure 1: Outcome of trial of VBAC.

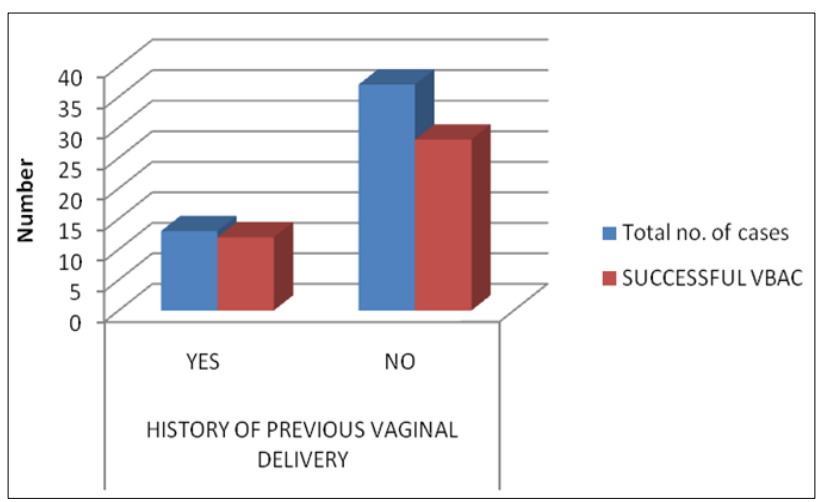

Figure 2: Success of trial of vaginal delivery in relation to past obstetric history (VBAC group).

\section{Indication of emergency LSCS in cases with failed VBAC}

The most common indication of emergency LSCS in our study in patients with failed VBAC was fetal distress (36.3\%) followed by scar tenderness $(27.2 \%)$, prolonged labour $(27.2 \%)$ and cord prolapse $(9 \%)$ (Table 1$)$.

Table 1: Indication of emergency LSCS in cases with failed VBAC.

\begin{tabular}{|ll|}
\hline Parameter & $\begin{array}{l}\text { Total No. } \\
\text { of cases }\end{array}$ \\
\hline $\begin{array}{l}\text { Signs of scar dehiscence \& } \\
\text { imminent scar rupture like } \\
\text { tachycardia, BPV etc. }\end{array}$ & $3(27 \%)$ \\
\hline Prolonged labour & $3(27 \%)$ \\
\hline Fetal distress & $4(36.3 \%)$ \\
\hline Cord prolapse & $1(9 \%)$ \\
\hline Total & $11(22 \%)$ \\
\hline
\end{tabular}

\section{Comparison of complications between successful VBAC and failed $V B A C$}

One patient in our study had anesthesia related complication. Three cases $(6 \%)$ had PPH, out of these, two patients $(18.1 \%)$ had emergency LSCS \& one $(2.56 \%)$ had successful VBAC. One patient $(9.09 \%)$ had vaginal tear. Three patients $(6 \%)$ received blood transfusion; out of them two were those who had emergency LSCS $(18.1 \%)$. In our study three patients (6\%) developed scar tenderness and were taken for emergency LSCS, out of them two had scar dehiscence and one patient was found to have rupture uterus. The febrile morbidity in our study was $14 \%$.

Table 2: Comparison of maternal complications between successful VBAC and failed VBAC.

\begin{tabular}{|c|c|c|c|c|c|c|}
\hline \multirow[t]{2}{*}{ Characteristic } & \multicolumn{2}{|c|}{ Successful VBAC } & \multicolumn{2}{|c|}{$\begin{array}{l}\text { Failed VBAC } \\
\text { (Emergency LSCS) }\end{array}$} & \multicolumn{2}{|c|}{$\begin{array}{l}\text { Total } \\
\text { cases }\end{array}$} \\
\hline & No. & $\%$ & No. & $\%$ & No. & $\%$ \\
\hline \multicolumn{7}{|l|}{ Immediate complications } \\
\hline a) Anaesthesia related complications & 0 & 0 & 1 & 9.09 & 1 & 2 \\
\hline b) $\mathrm{PPH}$ & 1 & 2.56 & 2 & 18.1 & 3 & 6 \\
\hline c) Cervical/vaginal tears & 1 & 2.56 & 0 & 0 & 1 & 2 \\
\hline d) Blood Transfusion & 1 & 2.56 & 2 & 18.1 & 3 & 6 \\
\hline \multicolumn{7}{|l|}{ e) Scar related complications: } \\
\hline Scar dehiscence & 0 & 0 & 2 & 18.1 & 2 & 4 \\
\hline Scar rupture & 0 & 0 & 1 & 9.09 & 1 & 2 \\
\hline \multicolumn{7}{|l|}{ Late complications } \\
\hline a) Febrile morbidity & 2 & 5.128 & 5 & 45.4 & 7 & 14 \\
\hline b) puerperal sepsis & 0 & 0 & 2 & 18.1 & 2 & 4 \\
\hline c) U.T.I & 3 & 7.692 & 2 & 18.1 & 5 & 10 \\
\hline d) Skin incision complications & 1 & 2.56 & 2 & 18.1 & 3 & 6 \\
\hline Hospital stay & 2 day & & $7-8$ & & & \\
\hline
\end{tabular}


It was found to be significantly less in successful VBAC group when compared with failed VBAC (5.128\% vs. $45.4 \%$, $\mathrm{P}$ value $<0.01$ ) however the difference was found significant statistically. When comparing successful \& failed VBAC group, puerperal sepsis was observed more often in patients with failed trial of vaginal delivery as compared to successful VBAC (18.1\% vs. $0 \%)$. In our study, patients who were taken for emergency LSCS had slightly lesser incidence of U.T.I than patients with successful VBAC $(18.1 \%$ vs. $6.97 \%)(\mathrm{P}$ value $=0.28)$. The skin incision complications were noticed more in patients undergoing emergency LSCS (18.1\%) as compared to patients who had successful VBAC $(2.56 \%)$.The difference was statistically significant $(\mathrm{P}$ value <0.02). Further, the duration of hospital stay associated with successful vaginal delivery was less (2 days) as compared to the emergency LSCS (8 days). (Table 2).

\section{Neonatal outcome}

In our study, $4 \%$ of neonates had a low APGAR score of $<7$ at 5 minutes $(9.09 \%$ in failed VBAC \& $2.56 \%$ in Successful VBAC cases). One neonate from successful VBAC patient $(2.56 \%)$ \& two (18.1\%) from failed VBAC suffered from respiratory distress $(\mathrm{P}$ value $=$ 0.87). In our study, $18.1 \%$ neonates were admitted in NICU in Failed VBAC cases as compared to successful VBAC (2.56\%) (P value 1) (Table 3).

Table 3: Neonatal outcome.

\begin{tabular}{|c|c|c|c|c|c|c|}
\hline \multirow[t]{2}{*}{ Characteristic } & \multicolumn{2}{|c|}{$\begin{array}{l}\text { Successful VBAC } \\
(\mathrm{N}=39)\end{array}$} & \multicolumn{2}{|c|}{$\begin{array}{l}\text { Failed VBAC } \\
(\mathrm{N}=11)\end{array}$} & \multicolumn{2}{|c|}{ Total } \\
\hline & No. & $\%$ & No. & $\%$ & No. & $\%$ \\
\hline APGAR score at 5 minute $<7$ & 1 & 2.56 & 1 & 9.09 & 2 & 4 \\
\hline Respiratory distress & 1 & 2.56 & 2 & 18.1 & 3 & 6 \\
\hline TTN & 0 & 0 & 1 & 9.09 & 1 & 2 \\
\hline Infection & 0 & 0 & 1 & 9.09 & 1 & 2 \\
\hline NICU stay & 1 & 2.56 & 2 & 18.1 & 3 & 6 \\
\hline Neonatal death & 0 & 0 & 0 & 0 & 0 & 0 \\
\hline
\end{tabular}

All the patients were followed up till the time of discharge for any complication \& treated accordingly. No maternal mortality was reported. Patients were followed up at 6 weeks and no major complications were noticed. Three neonates were admitted in NICU in view of respiratory distress $\&$ infection. They were discharged in healthy condition after one week. All the babies were followed up after six weeks and no major complication was noted.

\section{DISCUSSION}

The strongest modality to combat ever rising caesarean rate is VABC. A prospective study was carried out on 50 patients who were eligible for vaginal delivery after taking proper informed consent. Out of total 50 patients, $39(78 \%)$ had successful vaginal delivery and 11(22\%) patients had failed vaginal delivery and underwent emergency LSCS. This is in correlation with study of Flamm et al., $1984^{7}$ (79\%). In our study, significant association of success of VBAC was noted in patients with history of prior VBAC as compared to patients without history of prior VBAC (P value being <0.0001). This is in conformity of the finding of Weinstein et al $1996^{8}$ who had stated that history of previous vaginal delivery is a good prognostic indicator of VBAC in current pregnancy. In our study the commonest indication of emergency LSCS in patients with failed VBAC was fetal distress (36.3\%) and this is comparable with the finding of Merill et. al, $1978^{9}(40 \%)$. Next most common indications in our participants were Scar tenderness $(27.2 \%)$ followed by prolonged labour $(27.2 \%)$. These findings are supported by the study of Allahabadia, $1963^{10}(33 \%)$ who has reported higher percentage of patients who underwent emergency caesarean section for arrest of active phase of labour. In the study of Finley and Gibbs $1986,{ }^{11} 0.73 \%$ patients underwent caesarean section for uterine scar complications (scar dehiscence \& scar rupture). In our study the incidence of emergency LSCS for cord prolapse was around 9\% however Shakti et.al $2005^{12}$ has concluded that the incidence of cord prolapse as indication of emergency LSCS was $4.5 \%$ in their study. One patient $(9.09 \%)$ from failed VBAC group who had emergency LSCS in our study had anesthesia related complications. Pai Madhukar et al. ${ }^{13}$ stated that if a caesarean section is performed under emergency situation, the risk of surgery may be increased due to a number of factors. In the present study three cases $(6 \%)$ had PPH, out of them, two patients (11.6\%) had emergency LSCS \& one $(4.65 \%)$ had successful VBAC however slightly lower incidence was reported by Shah et al., $2007^{14}(1.001 \%)$ in successful VBAC. In our study one patient $(2 \%)$ had vaginal tear which was repaired and it was consistent with studies by Shakti et al., $2005^{12}$ which showed the similar incidence of cervical/vaginal tears. In the current study, three patients $(6 \%)$ received 
blood transfusion, out of them, two were those who had emergency LSCS (11.16\%) and one patient was given blood transfusion when she developed PPH following successful VBAC. This is in agreement with result of Naef et al., $1995^{15}$ study who showed incidence of blood transfusion as $4.6 \%$. In our study, out of 11 patients who had emergency LSCS, three (27.2\%) had scar complications. Scar dehiscence was seen in 2 patients $(18.01 \%)$ and one patient $(9.09 \%)$ had rupture of uterus. However Phelan et al., $1987^{16}$ has reported slightly less percentage of dehiscence in failed TOL group (5.1\%). As compared to our study, slightly lower incidence of scar rupture was reported in study by Yetman and Nolan in $1989^{17}(1.79 \%)$. In our study, febrile morbidity was $14 \%$, which is consistent with the finding of Rosen et al., $1991^{18}(14 \%)$. Febrile morbidity was found to be significantly less in successful VBAC group when compared with failed VBAC $(5.12 \%$ vs. $45.4 \%$, P value $<0.01)$. Skin incision complications were more in patients who had emergency LSCS $(11.6 \%)$ as compared to patients who had successful VBAC $(2 \%)$. The difference was statistically found to be significant ( $\mathrm{P}$ value $<0.02$ ). The hospital stay associated with successful vaginal delivery was less (2 days) as compared to emergency LSCS (8 days). It is consistent with the study of Pramod $\operatorname{kumar}^{19}$ et al. who showed that mean stay of hospital was 1-2 days in cases with successful vaginal delivery and 812 days for cases who had emergency LSCS. In the current study the mean birth weight was 2784.20 \pm $40.439 \mathrm{gm}$. It was similar to results of study by Ganitha $\mathrm{G}^{20}$ who showed the mean birth weight of $28526 \pm 390$ grams in neonates in trial of labour group. In our study, $4 \%$ of neonates had a low APGAR score of $<7$ at 5 minutes. The similar findings were reported in the study carried out by Socol \& Paceman $1993 .{ }^{21}$ In our study, 2 $(18.1 \%)$ neonates had NICU stay in failed VBAC cases as compared to Successful i.e. $2(2.56 \%)$. No maternal or neonatal death was reported in our study.

\section{CONCLUSIONS}

In carefully selected patients, under close supervision, VBAC can be safely carried out, thereby bringing down the rising caesarean rates.

Funding: No funding sources Conflict of interest: None declared

Ethical approval: The study was approved by the institutional ethics committee of Kasturba Hospital, New Delhi

\section{REFERENCES}

1. Cragin EB. Conservatism in obstetrics. NY Med J 1916;104:1-3.

2. DeMuylder X, Thiery M. The caesarean delivery rate can be safely reduced in developing country. Obstet Gynaecol. 1990;75:60.

3. Flamm BL, Goings JR, Liu Y, Wolde-Tsadik G. Elective repeat cesarean delivery versus trial of labor: a prospective multicenter study. Obstet Gynecol. 1994 Jun;83(6):927-32.

4. Phelan JP, Clark SL, Diaz F, Paul RH. Vaginal birth after cesarean. Am J Obstet Gynecol. 1987 Dec;157(6):1510-5.

5. Holland JG, Dupre AR, Blake PG, Martin RW, Martin JN Jr. Trial of labour after caesarean. J Obstet Gynecol. 1992;79:936.

6. Ritchie JWK. Obstetric operations and procedure. In: Whitfield CR, eds. Dewhurst's Textbook of Obstetrics and Gynaecology for Postgraduates. 5th ed. Oxford: Blackwell Science; 1995: 392-396.

7. Flamm BL, Dunnett C, Fischermann E, Quilligan EJ. Vaginal delivery following cesarean section: use of oxytocin augmentation and epidural anesthesia with internal tocodynamic and internal fetal monitoring. Am J Obstet Gynecol. 1984;148(6):759-63.

8. Weinstein DW, Benshushan A, Tanos V, Zilberstein R, Rojansky N. Predictive score for vaginal birth after cesarean section. Am J Obstet Gynecol. 1996;174:192-8.

9. Merrill BS, Gibbs CE. Planned vaginal delivery following cesarean section. Obstet Gynecol. 1978 Jul;52(1):50-2.

10. Allahabadia NK. Vaginal delivery following caesarean section. Am J Obstet Gynecol. 1963 Jan;85:241-9.

11. Finley BE, Gibbs CE. Emergent cesarean 118 deliveries in patients undergoing a trial of labor with a transverse lower-segment scar. Am J Obstet Gynecol. 1986;155(5):936-9.

12. Vardhan Shakti, Behera RC, Sandhu GS, Singh Anita, Bandhu HC. Vaginal birth after caesarean delivery. 2006 Jul/Aug;40(4):320-3.

13. Pai Madhukar. Medical interventions: caesarean sections as a case study. Econom Politic Wkly. 2000;35(31):2755-61.

14. Shah Jitesh Mafatlal, Mehta Meghana Narendrabhai. Analysis of mode of delivery in women with previous one caesarean section. J Obstet Gynecol India. 2009 Mar/Apr;59(2):136-9.

15. Naef RW 3rd, Ray MA, Chauhan SP, Roach H, Blake PG, Martin JN Jr. Trial of labor after caesarean delivery after caesarean delivery with a lower segment, vertical uterine incision: is it safe? Am J Obstet Gynaecol. 1995;172:1666-74.

16. Phelan JP, Clark SL, Diaz F, Paul RH. Vaginal birth after cesarean. Am J Obstet Gynecol. 1987 Dec;157(6):1510-5.

17. Yetman TJ, Nolan TE. Vaginal birth after cesarean section: a reappraisal of risk. Am J Obstet Gynecol. 1989;161:1119-23.

18. Rosen MG, Dickinson JC, Westhoff CL. Vaginal birth after cesarean: a meta-analysis of morbidity and mortality. Obstet Gynecol. 1991;77:465-70.

19. Pramod Kumar, Poonam Varma Shivkumar, Arpita Jaiswal. Subjective assessment of LSCS scar site for vaginal birth after caesarean trial and outcome in MGIMS. Int J Biol Med Res. 2012;3(2):1825-9. 
20. Ganitha G. Comparative study of immediate fetal outcome following trial of labour versus elective repeat cesarean section in a case of previous L.S.C.S with singleton pregnancy with vertex presentation. J Obstet Gynecol. 2005 Feb;10:2254.
21. Socol ML, Peaceman AM. Vaginal birth after cesarean: an appraisal of fetal risk. Obstet Gynecol. 1999;93:674-9.

DOI: $10.18203 / 2320-1770 . i j r \operatorname{cog} 20150069$

Cite this article as: Latika, Kaur G, Singh S. To study the maternal and perinatal outcome following vaginal birth after caesarean section after one previous lower segment caesarean section. Int J Reprod Contracept Obstet Gynecol 2015;4:658-63. 